OPEN ACCESS

Edited by:

Youhua Xu,

Macau University of Science and

Technology, Macau

Reviewed by:

Guilin Zhang,

Macau University of Science and

Technology, Macau

Yong Wang,

Beijing University of Chinese Medicine,

China

*Correspondence:

Hao Li

xyhplihao1965@126.com

Yu Cao

yu.cao-xiyuan@foxmail.com

${ }^{\text {t}}$ These authors have contributed equally to this work

Specialty section:

This article was submitted to Ethnopharmacology,

a section of the journal

Frontiers in Pharmacology

Received: 12 November 2019

Accepted: 28 January 2020

Published: 21 February 2020

Citation:

Wu M, Liu L, Xing Y, Yang S, Li H and

Cao Y (2020) Roles and Mechanisms of Hawthorn and lts Extracts on

Atherosclerosis: A Review.

Front. Pharmacol. 11:118.

doi: 10.3389/fphar.2020.00118

\section{Roles and Mechanisms of Hawthorn and Its Extracts on Atherosclerosis: A Review}

\author{
Min $\mathrm{Wu}^{1+}$, Longtao $\mathrm{Liu}^{2 \dagger}$, Yanwei Xing ${ }^{1}$, Shengjie Yang ${ }^{1}, \mathrm{Hao} \mathrm{Li}^{3 *}$ and $\mathrm{Yu} \mathrm{CaO}^{3 *}$ \\ 1 Guang'anmen Hospital, China Academy of Chinese Medical Sciences, Beijing, China, ${ }^{2}$ Xiyuan Hospital, China Academy of \\ Chinese Medical Sciences, Beijing, China, ${ }^{3}$ Institute of Geriatrics, Xiyuan Hospital, China Academy of Chinese Medical \\ Sciences, Beijing, China
}

Cardiovascular disease (CVD), especially atherosclerosis, is a leading cause of morbidity and mortality globally; it causes a considerable burden on families and caregivers and results in significant financial costs being incurred. Hawthorn has an extensive history of medical use in many countries. In China, the use of hawthorn for the treatment of CVD dates to 659 AD. In addition, according to the theory of traditional Chinese medicine, it acts on tonifying the spleen to promote digestion and activate blood circulation to dissipate blood stasis. This review revealed that the hawthorn extracts possess serum lipid-lowering, anti-oxidative, and cardiovascular protective properties, thus gaining popularity, especially for its antiatherosclerotic effects. We summarize the four principal mechanisms, including blood lipidlowering, anti-oxidative, anti-inflammatory, and vascular endothelial protection, thus providing a theoretical basis for further utilization of hawthorn.

Keywords: hawthorn, Crataegus, atherosclerosis, oxidative stress, inflammation, endothelial dysfunction

\section{INTRODUCTION}

Cardiovascular disease (CVD), especially atherosclerosis, is a leading cause of morbidity and mortality worldwide. CVD imposes a considerable burden on families and primary caregivers, along with a high financial cost to society. During past decades in China, ischemic heart disease and stroke are the top two causes of death (Yang et al., 2013). With a rapidly aging population, the absolute number of deaths due to CVD increased by $46 \%$ in China, a figure four and three times higher than those in the United States and Western Europe, respectively (Du et al., 2019). Beyond conventional medical treatment, herbal plants have several natural compounds for the prevention and treatment of various diseases. Herbal medicine, such as adjuvants, has also been popular worldwide. It is estimated by the World Health Organization that in the developing countries, nearly four billion people consume herbal medications as a primary source of healthcare (Bodeker and Ong, 2005). Therefore, the use of herbal remedies in complementary and alternative medicines has been widely embraced in many countries (Ekor, 2014).

Crataegus sp., commonly known as hawthorn, or hawberry, is a large genus of thorny shrubs and trees belonging to the family Rosaceae, comprising approximately 280 species, native to zones with a mild climate in Europe, East Asia, and North America (Hobbs and Foster, 1994). Hawthorn has been used for centuries worldwide as both food and folk medicine. Hawthorn is one of the recognized medicinal plants in European medicine, as Dioscorides primarily described its cardiovascular actions in the first century 
(Petrovska, 2012). Currently, countries such as China, Germany, and France have officially recorded some species in their pharmacopeias (Chang et al., 2002).

In China, the bright red berries of hawthorn, also called Shanzha (Figure 1), have been extensively used to treat various ailments given their medicinal properties. It was mentioned first for "treating dysentery" in Tang Materia Medica (Tang Ben Cao) dating back to $659 \mathrm{AD}$, the first known official pharmacopeia in the world. As described in the Compendium of Materia Medica (Bencao Gangmu), which is regarded as the most complete and comprehensive herbal monograph, the dried berry of Crataegus pinnatifida was described with healing efficacy for thoracalgia, hernia, indigestion, blood stagnation, and hematochezia (Liu et al., 2011). Currently, considerable efforts are underway to identify bioactive components from different parts of the plants and to unveil potential mechanisms of their pharmaceutical actions.

\section{Crataegus sp: Chemical Constituents, Pharmacology, Potential Applications, and Toxicity}

Presently, in traditional Chinese medicine (TCM), the fruits of both C. pinnatifida Bge. var. major N.E.Br and C. pinnatifida Bge are the only two medicinal species documented in Chinese pharmacopeia, which are used to promote digestion and improve blood circulation. Other species, such as Crataegus monogyna and C. azarolus, were also used as focal medicine in other countries. Different parts of the plant, i.e., flowers, leaves, seeds, and berries, have long been recorded for their traditional medical use in either decoction or powder form as folk medicine in many countries, such as Serbia, France, Chile, Turkey, and China, for the treatment of various diseases (e.g., antispasmodic, cardiotonic, diuretic, hypotensive, and anti-atherosclerotic) (Cloud et al., 2019; Dehghani et al., 2019).

In the past 20 years, greater than 150 chemical compounds, including flavonoids, triterpenoids, oligomeric proanthocyanidins, and organic acids, were separated and characterized in the berries, leaves, and flowers of C. pinnatifida (Özcan et al., 2005; Wu et al., 2014) (Figures 2-4). Moreover, the pectin in fresh hawthorn fruit was reported to be as high as 20.5\% (Wang et al., 2007). Pectin oligosaccharides with $2-11$ polymers show antioxidant, hypolipidemic, antiglycation, and antibiotic properties (Li et al., 2010; Li et al., 2013a; Li et al., 2014; Zhu et al., 2019). Interestingly, one study showed the contribution of total polyphenolics, rather than the total flavonoids or anthocyanins to the antioxidant capacity of the hawthorn drinks (made from C. pinnatifida) (Liu et al., 2016). Besides, heat and microwave exposure could increase the level of anthocyanins, such as cyanidin-3-galactoside (Liu et al., 2016). In other species such as C. monogyna and C. azarolus, similar types of phenolic compounds were present and categorized into four subclasses: phenolic acids including hydroxycinnamic acids and hydroxybenzoic acid, flavonoids, which are the most abundant components, including flavones and glucosylated flavonols, anthocyanins, such as glycosides of cyanidin, of which cyanidin3-O-glucoside is the most abundant (Mraihi et al., 2015). Another study identified seven neolignans in the ethanol extract of the $C$. pinnatifida seeds, which elicited antioxidant and anti-inflammatory effects (Peng et al., 2016).

These results show that hawthorn fruits could serve as promising healthcare supplements and also as a potential source of antioxidant and cardiotonic phenolic materials. One study identified the phenolic compounds in the Crataegus pubescens fruit, and the most abundant substances were (+)-catechin, (-)-epicatechin, and chlorogenic acid, which could be used as nutraceutical and functional foods (GonzálezJiménez et al., 2018).

With expanding global interest, modern research validated the presence of multiple biological and pharmacological activities in the extracts of hawthorn fruits, leaves, and flowers, including cardiovascular protective ability, hypolipidemic activity, and anti-oxidative capacity (Pittler et al., 2003; Wang H. et al., 2011; Zhang et al., 2014). WS ${ }^{\circledR} 1442$ is the most studied compound consisting of $20 \%$ oligomeric procyanidins extracted from the leaves and flowers (45\% ethanol extract) of C. monogyna and Crataegus laevigata (Holubarsch et al., 2008). In the United States and European countries, WS ${ }^{\circledR} 1442$ has been recommended for treating congestive heart failure stages I-III based on the classification of the New York Heart Association (NYHA) (Tauchert, 2002; Pittler et al., 2003).

Crataegus sp. has a long history of cardioprotective ability, which is extended for first-line clinical practice. Due to its

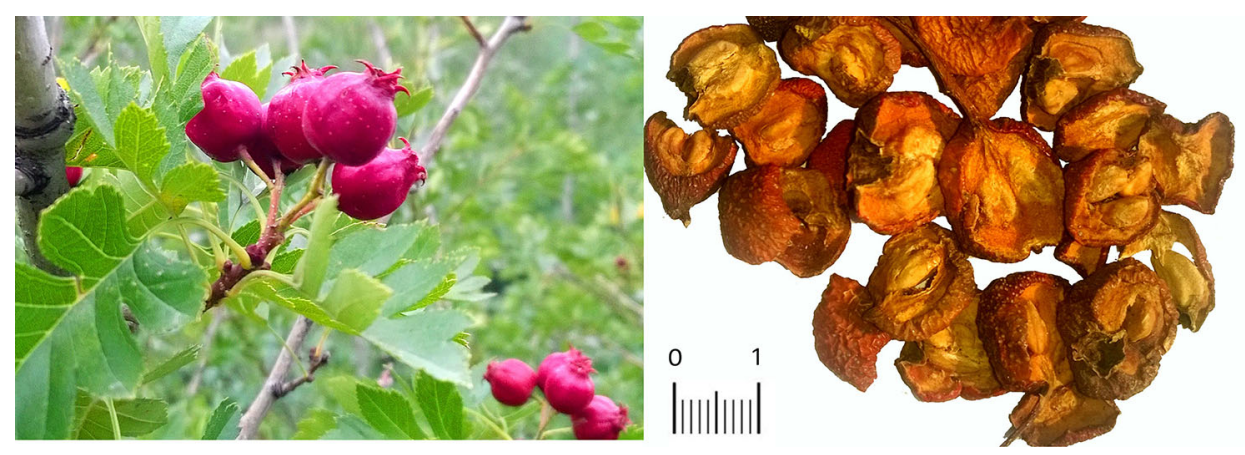

FIGURE 1 | Crataegus pinnatifida tree and fruits (left). Traditional Chinese herb Shanzha (Fructus Crataegus, prepared pieces of Crataegus pinnatifida var. major) fruit pieces (right). 


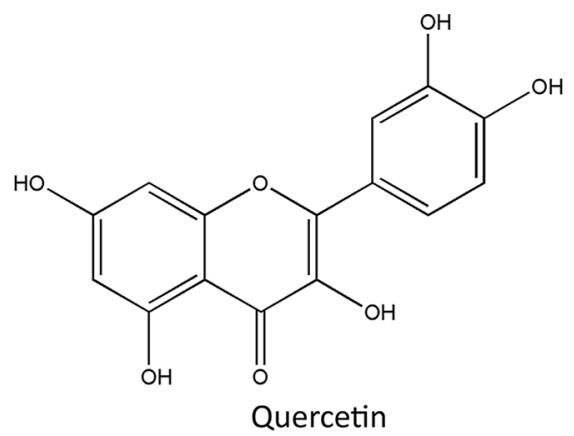<smiles>O=c1cc(-c2ccc(O)c(O)c2)oc2cc(O)cc(O)c12</smiles><smiles>O=c1c(O)c(-c2ccc(O)cc2)oc2cc(O)cc(O)c12</smiles><smiles></smiles>

FIGURE 2 | Chemical structures of representative flavonoids in Crataegus pinnatifida.

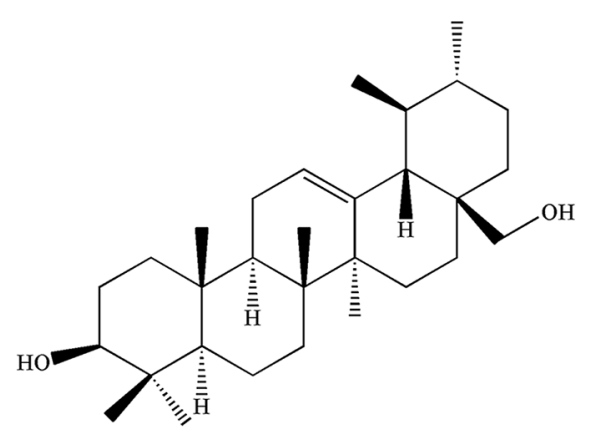

Ursolic acid

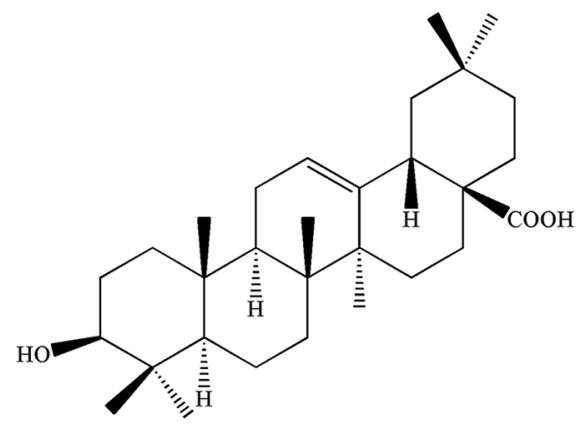

Oleanolic acid

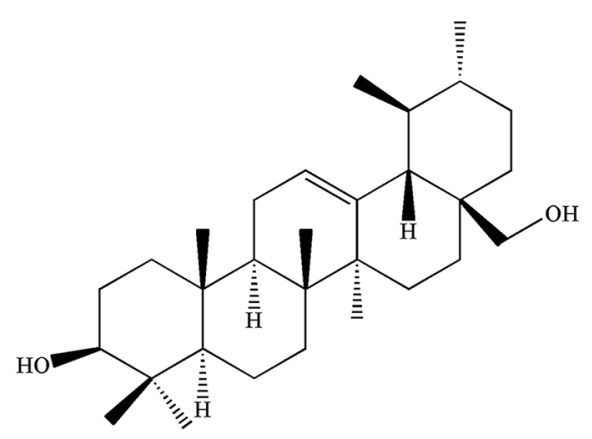

Uvaol

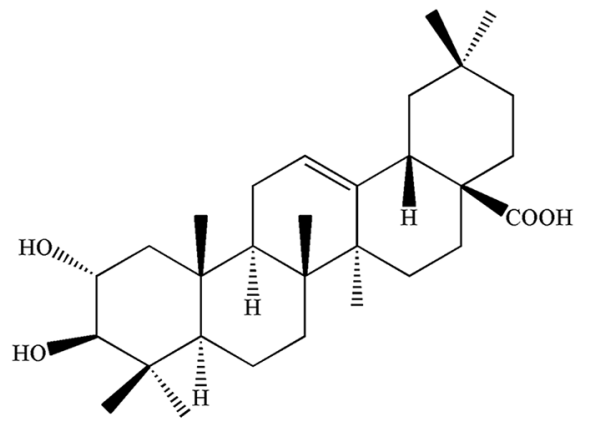

Crataegolic acid

FIGURE 3 | Chemical structures of representative triterpenoids in Crataegus pinnatifida. 


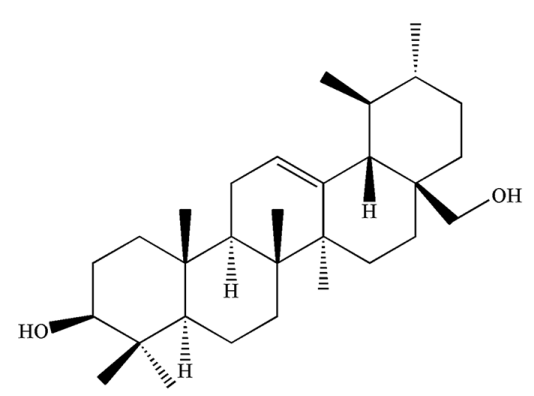

(+)-catechin

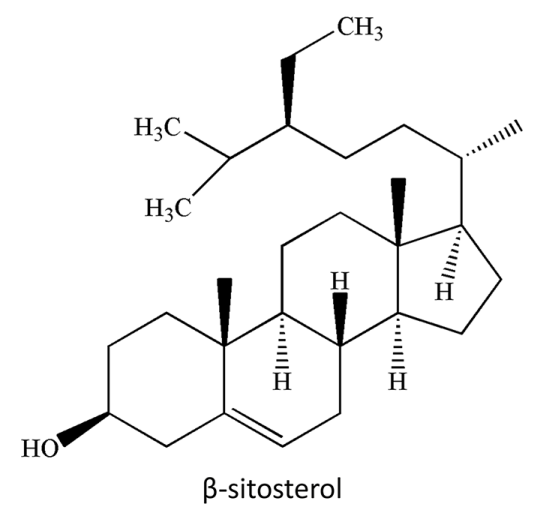<smiles>O=C(/C=C/c1ccc(O)c(O)c1)O[C@H]1C[C@@H](O)C[C@@](O)(C(=O)O)C1</smiles>

Chlorogenic acid<smiles>O=C(O)/C=C/c1ccc(O)c(O)c1</smiles>

Caffeic acid

FIGURE 4 | Chemical structures of other compounds in Crataegus pinnatifida.

popularity and efficacy, the extracts of Crataegus sp. were assessed in several clinical trials. In addition to its well-known cardiotonic properties, Crataegus oxyacantha has also been reported to exert various other pharmacological activities such as anxiolytic, hypotensive, hypolipidemic, antioxidant, hypoglycemic, immunomodulatory, and antimutagenic activities. This article focuses mainly on the anti-atherosclerotic effects of hawthorn and summarizes the mechanisms involved in these effects.

Although no adverse events are reported in its current clinical use, C. oxyacantha extracts exhibit genotoxic and mutagenic effects in different cultured cell lines (de Quadros et al., 2017), as well as mild genotoxicity in mice (Yonekubo et al., 2018). Intriguingly, several studies showed a protective effect of $C$. microphylla extracts on a variety of genotoxic insults in lymphoid lineage cells (Hosseinimehr et al., 2006; Hosseinimehr et al., 2008; Hosseinimehr et al., 2009; Hosseinimehr et al., 2011). These results suggest caution regarding prolonged or high-dose use.

\section{Hypolipidemic Activity}

CVDs have been the leading cause of mortality and morbidity globally for decades. The primary pathogenesis of CVDs is atherosclerosis, which could lead to dramatic clinical events, such as unstable angina or myocardial infarction (Reiner et al., 2011). The underlying pathophysiological mechanisms of atherosclerosis are oxidative stress damage, lipid deposition, inflammatory responses, and vascular endothelial dysfunction
(Libby et al., 2002; Weber and Noels, 2011). Multiple risk factors associated with the development of atherosclerotic plaque are diabetes mellitus, dyslipidemia, hypertension, obesity, and cigarette smoking (Folsom et al., 1997; Hackam and Anand, 2003; Mannarino and Pirro, 2008). Among the risk factors identified in epidemiological studies, only apolipoprotein (apo)-B containing lipoproteins, including low-density lipoproteins (LDLs) and verylow-density lipoproteins (VLDLs), cause atherosclerosis in both humans and experimental animals (Skålén et al., 2002).

Once the LDL traverses to the sub-endothelium, it binds to the chondroitin sulfate (CS) and dermatan sulfate (DS) site of the matrix proteoglycans, further leading to entrapment and phagocytosis by macrophages and other cells, eventually forming the foam cells and lipid core to initiate the local inflammatory response (Little et al., 2007). Lipid retention is an essential and critical initial step in the atherosclerotic cascade, and without this event, atherosclerosis could not be induced in animal models (Olofsson and Boren, 2005).

A 6-month clinical observation of 64 patients with carotid artery atherosclerosis showed that the ingestion of hawthorn extract at a dose of $5.0 \mathrm{mg} / \mathrm{kg}$ reduces the level of serum lipid and promotes plaque stability (Liu et al., 2014). C. pinnatifida extracts that primarily contain flavonoids showed promising hypolipidemic activity in different experimental animals. Flavonoid extracts from the leaves of $C$. pinnatifida considerably decreased level of the serum lipids, such as total cholesterol (TC) 
and triglyceride (TG) in rats, mice, and rabbits (Zhang et al., 2002b; Luo et al., 2009; Zhang et al., 2013). The reduction in the level of serum total cholesterol and TG is a complex process involving multiple steps in cholesterol metabolism. First, it inhibits cholesterol absorption by downregulating the expression and activity of intestinal acyl-CoA cholesterol acyltransferase (ACAT). Intestinal ACAT is a critical regulator involved in cholesterol absorption by esterification of cholesterol before absorption (Zhang et al., 2002a). Second, the total flavonoids attenuate the expression of two essential liver enzymes involved in lipid biosynthesis, hydroxy methylglutaryl coenzyme A reductase (HMG-CoA) and cholesterol-7-alpha-hydroxylase (CYP7 $\alpha$ ) (Zhang et al., 2002a; Kwok et al., 2013). Moreover, the total flavonoids of $C$. pinnatifida inhibit the mature adipocyte secretion of the leptin and plasminogen activator inhibitor (PAI)-1 (Liu et al., 2009c) and decrease adipogenesis-related gene expression, including sterol regulatory element-binding proteins-1c (SREBP), fatty acid synthase (FAS), triacylglycerol hydrolase (TGH), and hormone-sensitive TG lipase (HSL) (Xie et al., 2009). A more recent study showed consistent results using extracts derived from the leaves of C. pinnatifida [Hawthorn leaf flavonoids (HLF)]. HLF decreased serum lipid levels, including total TGs, cholesterols, and lipoproteins, such as VLDLs and LDLs in $\mathrm{Apoe}^{-/-}$mice due to the involvement of the hepatic lipid metabolism-related genes, including peroxisome proliferator-activated receptor (PPAR) $\alpha$, SREBP-1c, CPT-1, and HMG-CoAR reductase (Dong et al., 2017). In vitro data showed HLF inhibited the formation of foam cells by promoting cellular cholesterol efflux via the upregulation of the ATP-binding cassette transporter A1 (ABCA1), PPAR $\gamma$, and downregulation of $\mathrm{CD} 36$, thus preventing the progression of atherosclerotic lesions (Liu et al., 2009a). Another line of research showed that pectin oligosaccharides and pectin hydrolysates fractionated from C. pinnatifida could restore unbalanced cholesterol metabolism and serum lipid overload in mice or hamsters that are fed a high-fat diet (HFD) (Li et al., 2010; Li et al., 2014; Zhu et al., 2015). This is specifically by the involvement of hepatic enzymes, such as glycerol 3-phosphate acyltransferase (GPAT), SREBP-2, phosphatidate phosphohydrolase (PAP), cholesterol-7 $\alpha$-hydroxylase (Zhu et al., 2013; Li et al., 2014), and hepatic fatty acid oxidation-related enzyme activities of acyl-CoA oxidase, 3-ketoacyl-CoA thiolase, 2,4-dienoyl-CoA reductase, and carnitine palmitoyltransferase I (Li et al., 2013b), and these results are consistent with earlier reported data. For example, pectin pentaoligogalacturonide was shown to increase the expression of CYP7A1, bile salt export pump, but not the sodium-taurocholate co-transporting polypeptide (Zhu et al., 2017). Similarly, pectin also reportedly downregulated the abnormal activity of high fat-induced SREBF-1c, suppressing the protein expression levels, pyruvate kinase, acetyl-CoA carboxylase, and fatty acid synthase enzyme activities (Li et al., 2017). Altogether, these data showed that pectin and its derivatives may be promising candidates for the treatment of hyperlipidemia and atherosclerosis.

Most of the research was conducted with the European and East Asian species. There exists little knowledge on plants native to other parts of the world. One study on the extracts from berries and leaves of Crataegus chrysocarpa, a species native to
North America, showed that a reduced serum fasting LDL-C improved heart function by elevating the nitric oxide (NO) levels (Diane et al., 2016).

\section{Anti-Oxidative Activity}

Although elevated serum lipid levels are essential for atherosclerosis progression, LDLs in their native state cannot trigger the lipid retention cascade before oxidization by free radicals. Therefore, oxidative stress is crucial to illustrate atherogenic mechanisms. Oxidative stress is a state of unbalanced tissue oxidation due to the disturbed equilibrium between pro-oxidant and antioxidant molecules, an essential step in the pathophysiological development of atherosclerosis (Stocker and Keaney, 2004). Analysis of the atherosclerotic lesion compositions showed the oxidative products of protein and lipid such as F2 $\alpha$-isoprostanes, chlorinated lipid hydroperoxides, short-chain aldehydes, nitrated amino acids, oxidized phospholipids, and oxysterols as the major constituents (Heinecke, 1998). Recent studies, both in vivo and in vitro, showed that the extracts of $C$. pinnatifida eliminate free radicals to attenuate LDL oxidation (Wang T. et al., 2011; Cheng et al., 2013; Bedreag et al., 2014). In contrast to native LDLs, only the modified or oxidized LDLs can drive the development of atherosclerosis. It has been demonstrated that extracts from $C$. pinnatifida exert potent scavenging properties against $\mathrm{DPPH}$, hydroxyl radicals, and copper-II and peroxyl radical-induced LDL cholesterol oxidation (Zhang et al., 2001; Liu et al., 2009b), as well as hydrogen peroxide and superoxide species (Bahorun et al., 1996), which is partially due to interactions with antioxidant enzymes, such as superoxide dismutase (SOD) and glutathione peroxidase (GSH-px) (Wang W. et al., 2011; Zhang et al., 2014). The pectin oligosaccharides of the C. pinnatifida fruit also reduced the aberrant oxidative state in a mouse model of experimental hyperlipidemia, as indicated by reduced serum synthesis and accumulation of malondialdehyde and increased SOD levels (Li et al., 2010). Metabolomic results showed that seedless hawthorn fruit extracts increased the levels of 11 different metabolites related to oxidative responses, as well as the concentration of $\mathrm{NO}$ and the activity of NO synthase, which are known factors that prevent against oxidative impairments (Zheng et al., 2019). The mechanism may involve the nuclear factor erythroid 2-related factor (Nrf2)/heme oxygenase-1 (HO1) signaling pathway, major sentinels, and effectors in response to the oxidative status (Yoo et al., 2016). Similarly, another study provided evidence that the total flavones of hawthorn mitigate the endothelial cell impairment after coronary bypass graft operation by reducing the oxidative stress (Zhu et al., 2018). In addition, extracts of $C$. oxyacantha attenuate the ischemiareperfusion insults, and the potential mechanism might be attributed to a reduction in the oxidative stress level, which increases after ischemia-reperfusion injury (Ranjbar et al., 2018). Furthermore, vitexin (an extract from hawthorn leaves) suppressed doxorubicin (DOX)-induced oxidative stress, inflammation, apoptosis, and myocardial damage through a mechanism involving increased cellular expression of $\mathrm{p}$ FoxO3a (Sun et al., 2016). Thus, the Akt/FoxO3a signaling 
pathway may be a novel target for the development of drugs to reduce DOX-induced cardiotoxicity.

\section{Endothelium Protection}

Endothelium dysfunction is a well-known independent risk factor for coronary heart disease and is closely associated with its clinical outcome (Daiber et al., 2017). Endothelium dysfunction occurs in the early stages of atherogenesis, characterized by a reduction of NO-mediated vasodilator responses and increased vasoconstriction due to excess endothelin (ET)-1 synthesis, resulting in enhanced vascular permeability. Such alterations lead to increased cell permeability, the release of proinflammatory factors, such as adhesion molecules and cytokines leukocyte adherence, platelet hyper-activation, enhanced lowdensity lipoprotein oxidation, as well as vascular smooth muscle cell proliferation and migration (Corte et al., 2016; Costantino et al., 2016; Jamwal and Sharma, 2018).

Hawthorn extracts resulted in decreased ET-1 and elevated NO levels in both human and animal experiments (Asher et al., 2012; Zhang et al., 2013). Endothelial NO synthase (eNOS) is a critical regulator of NO synthesis. The translocation from the cell membrane results in increased phosphorylation of serine residue 1177 or decreased phosphorylation of threonine residue 495, which are pathways for activating eNOS. Hawthorn extracts could induce vasorelaxation by increasing the phosphorylation of serine residue 1177 (Brixius et al., 2006). Hawthorn extract WS ${ }^{\circledR} 1442$ increases cytosolic $\left[\mathrm{Ca}^{2+}\right]$ i by suppressing sarcoplasmic/endoplasmic reticulum $\mathrm{Ca}^{2+}$ ATPase (SERCA) and activating the inositol 1,4,5trisphosphate (IP3) pathway, but without affecting the barrier function or endothelial cell contraction. More importantly, it does not induce store-operated calcium entry (Willer et al., 2012).

In other pathological conditions attributed to atherogenesis, such as diabetes, aging, and hypertension, hawthorn extracts have shown a promising effect in maintaining the integrity and normal endothelial function both in vitro and in vivo (Xiyun and Yaofa, 2002; Bubik et al., 2012; Idris-Khodja et al., 2012; Peters et al., 2012; Topal et al., 2013).

\section{Anti-Inflammatory Activity}

Over the past decades, lipid retention and oxidation are regarded as the sine qua non of the atherosclerosis (Moriya, 2019), and how and where the lipid oxidation occurs have not been identified. Chemical analysis of the modified lipids and proteins, using human atheroma samples, does not necessarily correspond to the transition metal-mediated oxidized lipoproteins in vitro; also, randomized clinical trials failed to validate the effectiveness of antioxidant therapy (Pascual-Teresa et al., 2010; Myung et al., 2013).

Recent atherosclerosis studies focused on inflammation, thus providing new insight into the mechanisms of this disease. Inflammation participates at all stages of atherosclerosis development. Clinical research has identified the critical role of inflammation in the development and progression of coronary artery disease. Immune cells are present in early atherosclerotic lesions, and their effector chemicals drive the development of the lesions. The hyper-activated inflammatory response can lead to acute coronary syndromes (Gimbrone and García-Cardeña, 2016; Ferrucci and Fabbri, 2018; Ridker, 2019). Our previous study showed that hawthorn extracts alleviated atherosclerosis by inhibiting inflammation and apoptosis-related factors (Wang et al., 2019).

An in vitro study on mouse macrophage cell line showed that an aqueous extract of hawthorn fruit suppressed expression of inflammatory cytokines, such as interleukin (IL)-1 $\beta$, tumor necrosis factor (TNF)- $\alpha$, and IL-6 (Kim et al., 2011), which may be regulated by the nuclear factor $(\mathrm{NF})-\kappa \mathrm{B}$, a well-known mediator for its role in pro- and anti-inflammatory regulation and for controlling the expression of inflammatory genes including adhesion molecules, cytokines, and chemokines. Data from Crataegus aronia extracts showed inhibition of the nuclear accumulation of NF- $\kappa B$ and NLRP-3 protein levels and caspase1 in HFD-induced aortic vascular inflammation in rats, thus suggesting inhibition of the NLRP3 inflammasome-mediated pathway (Shatoor and Al Humayed, 2019). The monocyte/ macrophage is a major immunocyte involved in atherosclerosis, which scavenges modified LDLs and accelerates the local inflammatory response (Kao et al., 2005). One study reported that water extracts of $C$. pinnatifida inhibited NO production and inflammatory gene expression, including TNF- $\alpha$, COX-2, IL-1 $\beta$, and IL-6 in lipopolysaccharide (LPS)-stimulated RAW 264.7 cells (Li and Wang, 2011). In addition, ethanol extracts of $C$. pinnatifida seeds elicit a potent NO and TNF- $\alpha$ inhibitory effect, hence regarded as a promising and reliable source of antioxidants and inhibitors of inflammation (Peng et al., 2016). Clinical evidence showed that when metformin was combined with hawthorn, the level of body mass index (BMI), HbAlc, FPG, 2hPG, TG, and hsCRP remarkably reduced in patients with prediabetes complicated by nonalcoholic fatty liver disease (Gao et al., 2019). Altogether, these studies demonstrate that hawthorn extracts may be a promising drug for the treatment and prevention of atherosclerosis.

In addition to the activities mentioned above, the newly identified norditerpenoids from the leaves of $C$. pinnatifida exert antithrombotic activities both in vitro and in vivo (Gao et al., 2017). The norditerpenoids prevent adenosine diphosphate-induced platelet accumulation, mediated in response to the purinergic $\mathrm{P} 2 \mathrm{Y}$ receptor, and delay thrombocyte aggregation induced by $\mathrm{FeCl}_{3}$ in the caudal vessels of zebrafish (Gao et al., 2017). Antiplatelet and antithrombotic treatment is a critical approach for the treatment of acute coronary artery syndrome and secondary prevention of coronary heart disease, as recommended by the global guidance for CVD (Vandvik et al., 2012; Stewart et al., 2017).

However, hawthorn ingestion could lead to higher bleeding risk, and a clinical study of patients who underwent cardiac surgery reported that hawthorn extract consumption may increase the postoperative bleeding rate, the amount of chest tube output after cardiac surgery, and most importantly, the overall mortality (Rababa'h et al., 2016). Since the use of antiplatelet and antithrombotic medications are quite common in the treatment of CVDs, such as atherosclerosis, arrhythmia, and post-percutaneous coronary intervention, patients with such diseases should exercise caution while using hawthorn as an adjuvant medication. Further high-grade evidence is also 
required to assess the safety of hawthorn products in the treatment of CVDs.

Apart from these actions, one more recent study showed that a 16-week oral administration of C. pinnatifida leaf extracts suppressed the overall apoptotic level in the aorta, as indicated by the alternations of the expressions of Bcl-2 (B-cell lymphoma 2) and BAX (BCL2-associated X protein) (Wang et al., 2019). Besides, hawthorn extracts were reported to process an antiapoptotic effect in ischemic myocardial damage (Jayachandran et al., 2010; Ranjbar et al., 2018), a common result due to atherosclerotic lesions invading coronary arteries. This may attribute to the activation of Akt and HIF-1 (hypoxia-inducible factors) signaling pathways (Jayachandran et al., 2010). Myocardial apoptosis is known as a key pathological feature under ischemic conditions. Strategies against apoptotic cascades have been proposed for the treatment of ischemic heart disease (Perricone and Vander Heide, 2014). To this end, hawthorn extracts may be promising complementation for the treatment of cardiac ischemic injuries as well as post myocardial infarction rehabilitation. (The cardiovascular effects are shown in Table 1 and Figure 5.)

\section{CONCLUSIONS}

Medicinal plants possessing considerable quantities of therapeutic natural products are considered a promising source of medicine and chemicals. Herbal plants are becoming the topselling phytotherapeutics globally. A plethora of preclinical studies have shown that hawthorn extracts possess cardioprotective and anti-atherosclerotic properties and contain major bioactive components identified as flavonoids, polyphenols, and oligomeric procyanidins. The underlying mechanisms are associated with reduced serum lipid contents, which involve inhibition of lipid absorption in intestines and cholesterol de novo synthesis in the liver, as well as promoting cholesterol efflux, which subsequentially suppresses lipid retention and plaque formation. Reduced lipid

TABLE 1 | Major effects and targets of Crataegus in atherosclerosis

\begin{tabular}{|c|c|c|c|c|c|}
\hline Effects & Species & Materials & Subjects & Targets & Reference \\
\hline \multirow{10}{*}{$\begin{array}{l}\text { Lipid-lowering } \\
\text { effect }\end{array}$} & \multirow[t]{9}{*}{ C. pinnatifida } & Freeze-dried fruit & $\mathrm{ApoE}^{-/-}$mice & ACAT & Zhang et al., 2014 \\
\hline & & powder & & SREBP-1C & \\
\hline & & & & HMG-CoAR, CYP7 $\alpha$ & \\
\hline & & & & FAS & \\
\hline & & & & $\mathrm{PPAR} \alpha, \mathrm{CPT}-1$ & \\
\hline & & Fruit powder & New Zealand rabbits & $\begin{array}{l}\text { HMG-CoAR, CYP7 } \alpha \\
\text { ACAT }\end{array}$ & Zhang et al., 2002b \\
\hline & & Ethanol extracts & Syrian golden hamsters & HMG-CoAR & Zhang et al., 2002a \\
\hline & & & & ACAT & \\
\hline & & Total flavonoids & 3T3-L1 cells & Leptin & Liu et al., 2009c \\
\hline & $\begin{array}{l}\text { C. pinnatifida var. } \\
\text { major }\end{array}$ & $\begin{array}{l}50 \% \text { ethanol } \\
\text { extracts of leaf }\end{array}$ & Macrophage of $\mathrm{ApoE}^{-/-}$mice & PPAR $\gamma$, ABCA1, CD36 & Liu et al., 2009a \\
\hline \multirow[t]{2}{*}{$\begin{array}{l}\text { Antioxidant } \\
\text { effect }\end{array}$} & C. pinnatifida & $\begin{array}{l}\text { Freeze-dried fruit } \\
\text { powder }\end{array}$ & $\mathrm{ApoE}^{-/-}$mice & SOD1, SOD2, Gpx3 & Zhang et al., 2014 \\
\hline & $\begin{array}{l}\text { C. pinnatifida var. } \\
\text { major }\end{array}$ & $\begin{array}{l}\text { Aqueous extracts of } \\
\text { fruits }\end{array}$ & Wistar rats & SOD, MDA & $\begin{array}{l}\text { Wang W. et al., } \\
2011\end{array}$ \\
\hline \multirow{5}{*}{$\begin{array}{l}\text { Endothelial } \\
\text { protection }\end{array}$} & \multirow{5}{*}{$\begin{array}{l}\text { C. pinnatifida var. } \\
\text { major } \\
\text { C. monogyna and C. } \\
\text { laevigata }\end{array}$} & \multirow[t]{2}{*}{ Aqueous extracts } & \multirow{2}{*}{ Wistar rats } & $\mathrm{NO}, \mathrm{ET}$ & \multirow[t]{2}{*}{ Zhang et al., 2013} \\
\hline & & & & 6-keto-PGF1 $\alpha$, TXB2 & \\
\hline & & \multirow[t]{3}{*}{$W^{\circledR} 1442$} & $\begin{array}{l}\text { Rat aorta and human internal } \\
\text { mammary artery }\end{array}$ & Serine 1177 residual of eNOS & Brixius et al., 2006 \\
\hline & & & HUVECs, C57 mice & $\begin{array}{l}\text { cAMP/Epac1/Rap1 pathway } \mathrm{Ca}^{2+} / \mathrm{PKC} / \mathrm{RhoA} \\
\text { signaling pathway }\end{array}$ & Bubik et al., 2012 \\
\hline & & & HUVECs & $\begin{array}{l}\text { IP3 Sarcoplasmic/endoplasmic reticulum } \mathrm{Ca}^{2+} \\
\text { ATPase }\end{array}$ & Willer et al., 2012 \\
\hline \multirow{6}{*}{$\begin{array}{l}\text { Anti- } \\
\text { inflammatory } \\
\text { effect }\end{array}$} & \multirow[t]{3}{*}{$\begin{array}{l}\text { C. pinnatifida var. } \\
\text { major }\end{array}$} & $\begin{array}{l}50 \% \text { ethanol } \\
\text { extracts of leaf }\end{array}$ & $\begin{array}{l}\text { Carotid artery atherosclerosis } \\
\text { patients }\end{array}$ & CRP & Liu et al., 2014 \\
\hline & & Aqueous extracts of & Wistar rats & IL-18 & Zhang et al., 2013 \\
\hline & & fruits & & CRP, IL-1 $\beta, I L-8$ & \\
\hline & C. oxyacantha & Hawthorn vinegar & Cardiovascular risk patients & CRP & Kadas et al., 2014 \\
\hline & $\begin{array}{l}\text { C. pinnatifida var. } \\
\text { typica }\end{array}$ & Methanol extracts & RAW 264.7 cell & TNF- $\alpha, I L-1 \beta, I L-6$ & Tauchert, 2002 \\
\hline & $\begin{array}{l}\text { C. pinnatifida var. } \\
\text { major }\end{array}$ & $\begin{array}{l}50 \% \text { ethanol } \\
\text { extracts of leaf }\end{array}$ & $\mathrm{ApoE}^{-/-}$mice & $\mathrm{CRP}, \mathrm{NF}-\kappa \mathrm{B}$ & $\begin{array}{l}\text { Zheng and Wang, } \\
2010\end{array}$ \\
\hline \multirow[t]{2}{*}{$\begin{array}{l}\text { Anti-apoptotic } \\
\text { effect }\end{array}$} & $\begin{array}{l}\text { C. pinnatifida var. } \\
\text { major }\end{array}$ & $\begin{array}{l}50 \% \text { ethanol } \\
\text { extracts }\end{array}$ & $\mathrm{ApoE}^{-/-}$mice & $\mathrm{BAX}, \mathrm{Bcl}-2$ & Wang et al., 2019 \\
\hline & C. oxyacantha & Heartcare ${ }^{\mathrm{TM}}$ tablets & Wistar rats & Akt and HIF-1 signaling pathways & $\begin{array}{l}\text { Jayachandran } \\
\text { et al., } 2010\end{array}$ \\
\hline
\end{tabular}

6-keto-PGF1 $\alpha$, 6-keto-prostaglandin F1 $\alpha$; ABCA1, ATP-binding cassette transporter 1; ACAT, acyl-CoA cholesterol acyltransferase; BCl-2, B-cell lymphoma 2; BAX, BCL2-associatedX protein; CPT-1, carnitine palmitoyltransterase-1; CRP, C-reactive protein; ET, endothelin; Gpx3, glutathione peroxidase 3; HIF-1, hypoxia-inducible factor 1; HUVECs, human umbilical vein endothelial cells; MDA, malondialdehyde; NF- $\mathrm{kB}$, nuclear factor $\kappa B$; NO, nitric oxide; PPAR, peroxisome proliferator-activated receptor; SOD, superoxide dismutase; TNF- $\alpha$, tumor necrosis factor $\alpha$; TXB2, thromboxane B2. 


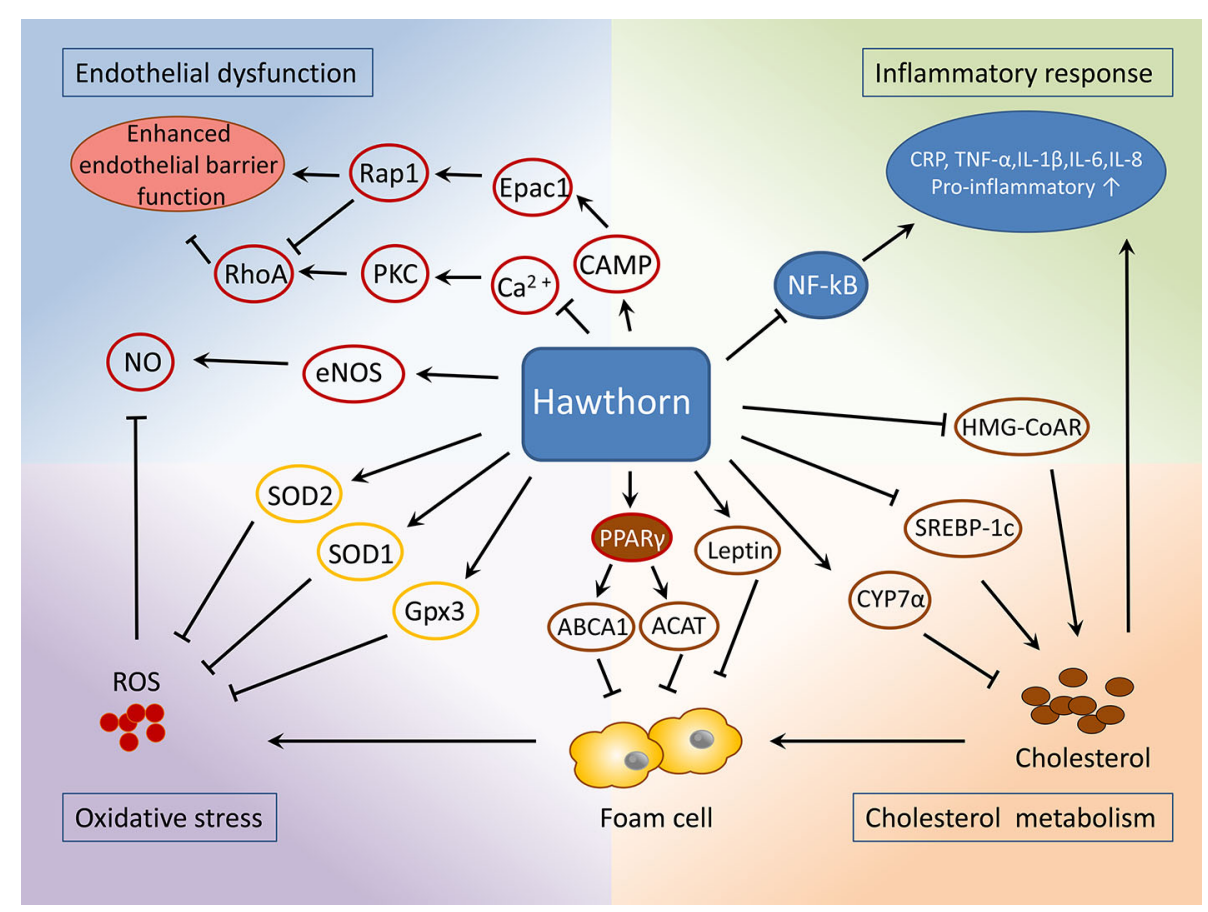

FIGURE 5 | Mechanisms of the protective role of hawthorn in the treatment of atherosclerosis.

retention then results in a lower number of foam cells, which is the major source of reactive oxygen species (ROS) and inflammatory cytokines. This also helps to maintain the normal function of endothelial cells, including its permeability, which in turn halts the lipid and circulating macrophage/monocyte infiltration.

These cardioprotective actions of the hawthorn target various pathological conditions associated with atherosclerosis, which may offer great potential for synergistic effects. In addition to these experimental data, a great deal of knowledge has been acquired regarding the benefits of hawthorn on other CVDs, including heart failure and primary hypertension (Wang et al., 2013; Holubarsch et al., 2018). However, little known is about its effects on coronary atherosclerosis in the clinical arena.

The current guidelines for the treatment of acute coronary syndrome and secondary prevention recommend medications such as inhibitor of platelet activation and aggregation, lipid modification drugs, $\beta$-blockers, and inhibitors of the reninangiotensin-aldosterone system (RAAS) (Amsterdam et al., 2014; Roffi et al., 2016; Chinese Medical Association Cardiovascular Branch \& Editorial Board of Chinese Journal of Cardiovascular Diseases, 2017). The biological effects of hawthorns may serve the needs of these strategies. The pathophysiology of atherosclerosis is complex; therefore, a therapeutic approach capable of targeting multiple arms of the cardioprotective aspects would likely elicit greatest efficacy in reducing the morbidity and mortality associated with atherosclerosis. However, the lack of investigation on its synergistic effects, and explanations on the specific underlying mechanisms, raises controversies with respect to its therapeutic efficacy. This calls for further clarification on whether the mixture of hawthorn extracts may exert synergistic benefits compared to the pure compound or rather exacerbate side effects.

It is worth noting that extracts from hawthorn leaves have been recorded in the European pharmacopoeia (European Pharmacopoeia, 2017) and in the pharmacopoeia of the People's Republic of China (Chinese Pharmacopoeia Commission, 2015), such as WS ${ }^{\circledR} 1442$ which has been extensively investigated in both preclinical and clinical studies. However by now, none of its effects on patients with coronary heart disease was reported. In China, several hawthorn leaf products for the treatment of angina and coronary heart disease have been approved by the National Medical Products Administration for sale (http://www.nmpa.gov.cn/WS04/ CL2042/). Nevertheless, clinical and pharmacological data of these drugs are not enough to evaluate its efficacy at the present moment.

Furthermore, the current consensus on the primary and secondary prevention of coronary heart disease requires longterm use of various medications interacting with multiple targets. The combined application of the hawthorn with other medications may give rise to unexpected effects. Hence, highquality trials with long-term follow-up are warranted to provide more compelling evidence of its safety and efficacy.

Taken together, the cardiovascular activities and clinical implications of hawthorn extracts have been extensively studied. Current evidence shows its potential as a phytotherapeutic agent adjuvant in conventional management of coronary heart disease. This requires further efforts to explore its clinical efficacy and safety for the treatment of atherosclerosis. 


\section{AUTHOR CONTRIBUTIONS}

MW and LL contributed equally to this manuscript. YC, HL, MW, LL, SY, and YX participated in the conception of the review. YC and HL drafted the initial full manuscript. MW and LL edited the manuscript.

\section{REFERENCES}

Özcan, M., Hacıseferoğulları, H., Marakoğlu, T., and Arslan, D. (2005). Hawthorn (Crataegus spp.) fruit: some physical and chemical properties. J. Food Eng. 69, 409-413. doi: 10.1016/j.jfoodeng.2004.08.032

Amsterdam, E. A., Wenger, N. K., Brindis, R. G., Casey, D. E., Ganiats, T. G., Holmes, D. R., et al. (2014). 2014 AHA/ACC guideline for the management of patients with non-ST-elevation acute coronary syndromes: a report of the american college of cardiology/american heart association task force on practice guidelines. J. Am. Coll. Cardiol. 64, e139-e228. doi: 10.1161/ CIR.0000000000000134

Asher, G. N., Viera, A. J., Weaver, M. A., Dominik, R., Caughey, M., and Hinderliter, A. L. (2012). Effect of hawthorn standardized extract on flow mediated dilation in prehypertensive and mildly hypertensive adults: a randomized, controlled cross-over trial. BMC Complem. Altern. Med. 12, 26. doi: 10.1186/1472-6882-12-26

Bahorun, T., Gressier, B., Trotin, F., Brunet, C., Dine, T., Luyckx, M., et al. (1996). Oxygen species scavenging activity of phenolic extracts from hawthorn fresh plant organs and pharmaceutical preparations. Arzneimittelforsch 46, 1086-1089.

Bedreag, C. F., Trifan, A., Vasincu, A., Miron, S. D., Aprotosoaie, A. C., and Miron, A. (2014). In vitro screening of Crataegus succulenta extracts for free radical scavenging and 15-lipoxygenase inhibitory activities. Rev. Med. Chir. Soc Med. Nat. Iasi 118, 544-550.

Bodeker, G., and Ong, C. K. (2005). WHO global atlas of traditional, complementary and alternative medicine (Kobe, Japan: World Health Organization).

Brixius, K., Willms, S., Napp, A., Tossios, P., Ladage, D., Bloch, W., et al. (2006). Crataegus special extract WS ${ }^{\circledR} 1442$ induces an endothelium-dependent, NOmediated vasorelaxation via eNOS-phosphorylation at serine 1177. Cardiovasc. Drugs Ther. 20, 177-184. doi: 10.1007/s10557-006-8723-7

Bubik, M. F., Willer, E. A., Bihari, P., Jürgenliemk, G., Ammer, H., Krombach, F., et al. (2012). A novel approach to prevent endothelial hyperpermeability: the Crataegus extract WS ${ }^{\circledR} 1442$ targets the cAMP/Rap1 pathway. J. Mol. Cell Cardiol. 52, 196-205. doi: 10.1016/j.yjmcc.2011.10.020

Chang, Q., Zuo, Z., Harrison, F., and Chow, M. S. S. (2002). Hawthorn. J. Clin. Pharmacol. 42, 605-612. doi: 10.1177/00970002042006003

Cheng, N., Wang, Y., Gao, H., Yuan, J., Feng, F., Cao, W., et al. (2013). Protective effect of extract of Crataegus pinnatifida pollen on DNA damage response to oxidative stress. Food Chem. Toxicol. 59, 709-714. doi: 10.1016/ j.fct.2013.07.015

Chinese Medical Association Cardiovascular Branch, Editorial Board of Chinese Journal of Cardiovascular Diseases (2017). Guidelines for the diagnosis and treatment of non - ST - segment elevation acute coronary syndrome, (2016). Chin. J. Cardiol. 45, 359-376. doi: 10.3760/cma.j.issn.0253-3758.2017.05.003

Chinese Pharmacopoeia Commission (2015). Pharmacopoeia of the People's Republic of China. Part I (Beijing: China Medical Science Press).

Cloud, A. M. E., Vilcins, D., and McEwen, B. J. (2019). The effect of hawthorn (Crataegus spp.) on blood pressure: a systematic review. Adv. Integr. Med. doi: 10.1016/j.aimed.2019.09.002

Corte, V. D., Tuttolomondo, A., Pecoraro, R., Di Raimondo, D., Vassallo, V., and Pinto, A. (2016). Inflammation, endothelial dysfunction and arterial stiffness as therapeutic targets in cardiovascular medicine. Curr. Pharm. Des. 22, 46584668. doi: 10.2174/1381612822666160510124801

Costantino, S., Paneni, F., and Cosentino, F. (2016). Ageing, metabolism and cardiovascular disease. J. Physiol. 594, 2061-2073. doi: 10.1113/JP270538

Daiber, A., Steven, S., Weber, A., Shuvaev, V. V., Muzykantov, V. R., Laher, I., et al. (2017). Targeting vascular (endothelial) dysfunction. Br. J. Pharmacol. 174, 1591-1619. doi: 10.1111/bph.13517

\section{FUNDING}

This work was funded by the Beijing Natural Science Foundation (No.7172185), the National Key R\&D Program of China (2018YFC1704901), and the National Natural Science Foundation of China (No. 81202805, 81973689, and 81573821).

de Quadros, A. P. O., Mazzeo, D. E. C., Marin-Morales, M. A., Perazzo, F. F., Rosa P. C. P., and Maistro, E. L. (2017). Fruit extract of the medicinal plant Crataegus oxyacantha exerts genotoxic and mutagenic effects in cultured cells. J. Toxicol. Environ. Health A. 80, 161-170. doi: 10.1080/15287394. 2016.1272517

Dehghani, S., Mehri, S., and Hosseinzadeh, H. (2019). The effects of Crataegus pinnatifida (Chinese hawthorn) on metabolic syndrome: a review. Iran J. Basic Med. Sci. 22, 460-468. doi: 10.22038/IJBMS.2019.31964.7678

Diane, A., Borthwick, F., Wu, S., Lee, J., Brown, P. N., Dickinson, T. A., et al. (2016). Hypolipidemic and cardioprotective benefits of a novel fireberry hawthorn fruit extract in the JCR: LA-cp rodent model of dyslipidemia and cardiac dysfunction. Food Funct. 7, 3943-3952. doi: 10.1039/C6FO01023G

Dong, P., Pan, L., Zhang, X., Zhang, W., Wang, X., Jiang, M., et al. (2017). Hawthorn (Crataegus pinnatifida Bunge) leave flavonoids attenuate atherosclerosis development in apoE knock-out mice. J. Ethnopharmacol. 198, 479-488. doi: 10.1016/j.jep.2017.01.040

Du, X., Patel, A., Anderson, C. S., Dong, J., and Ma, C. (2019). Epidemiology of Cardiovascular Disease in China and Opportunities for Improvement: JACC International. J. Am. Coll. Cardiol. 73, 3135-3147. doi: 10.1016/ j.jacc.2019.04.036

Ekor, M. (2014). The growing use of herbal medicines: issues relating to adverse reactions and challenges in monitoring safety. Front. Pharmacol. 4, 177. doi: 10.3389/fphar.2013.00177

European Pharmacopoeia (2017). Europäisches Arzneibuch Vol. 9.0 (Stuttgart, Germany: Deutscher Apotheker Verlag), 2359-2360.

Ferrucci, L., and Fabbri, E. (2018). Inflammageing: chronic inflammation in ageing, cardiovascular disease, and frailty. Nat. Rev. Cardiol. 15, 505-522. doi: 10.1038/s41569-018-0064-2

Folsom, A. R., Wu, K. K., Rosamond, W. D., Sharrett, A. R., and Chambless, L. E. (1997). Prospective study of hemostatic factors and incidence of coronary heart disease: the Atherosclerosis Risk in Communities (ARIC) Study. Circulation 96, 1102-1108. doi: 10.1161/01.CIR.96.4.1102

Gao, P. Y., Li, L. Z., Liu, K. C., Sun, C., Sun, X., Wu, Y. N., et al. (2017). Natural terpenoid glycosides with in vitro/vivo antithrombotic profiles from the leaves of Crataegus pinnatifida. Rsc Adv. 7, 48466-48474. doi: 10.1039/C7RA10768D

Gao, Z., Xie, M., Wang, N., Chen, L., and Huang, X. (2019). Effects of combination treatment of metformin and hawthorn in patients with prediabetes complicated by nonalcoholic fatty liver disease. Int. J. Clin. Exp. Med. 12, 1979-1984.

Gimbrone, M. A. Jr., and García-Cardeña, G. (2016). Endothelial cell dysfunction and the pathobiology of atherosclerosis. Circ. Res. 118, 620-636. doi: 10.1161/ CIRCRESAHA.115.306301

González-Jiménez, F. E., Salazar-Montoya, J. A., Calva-Calva, G., and RamosRamírez, E. G. (2018). Phytochemical characterization, in vitro antioxidant activity, and quantitative analysis by micellar electrokinetic chromatography of hawthorn (Crataegus pubescens) fruit. J. Food Qual. 2018, 2154893. doi: $10.1155 / 2018 / 2154893$

Hackam, D. G., and Anand, S. S. (2003). Emerging risk factors for atherosclerotic vascular disease: a critical review of the evidence. JAMA 290, 932-940. doi: 10.1001/jama.290.7.932

Heinecke, J. W. (1998). Oxidants and antioxidants in the pathogenesis of atherosclerosis: implications for the oxidized low density lipoprotein hypothesis. Atherosclerosis 141, 1-15. doi: 10.1016/S0021-9150(98)00173-7

Hobbs, C., and Foster, S. (1994). Hawthorn: a literature review. Herbal Gram. 22, 19-33.

Holubarsch, C. J., Colucci, W. S., Meinertz, T., Gaus, W., Tendera, M., Survival,, et al. (2008). The efficacy and safety of Crataegus extract WS ${ }^{\circledR} 1442$ in patients 
with heart failure: the spice trial. Eur. J. Heart Fail. 10, 1255-1263. doi: 10.1016/ j.ejheart.2008.10.004

Holubarsch, C. J., Colucci, W. S., and Eha, J. (2018). Benefit-risk assessment of Crataegus extract WS 1442: an evidence-based review. Am. J. Cardiovasc. Drug 18, 25-36. doi: 10.1007/s40256-017-0249-9

Hosseinimehr, S. J., Azadbakht, M., Mousavi, S. M., Mahmoudzadeh, A., and Akhlaghpoor, S. (2006). Radioprotective effects of hawthorn fruit extract against gamma irradiation in mouse bone marrow cells. J. Radiat. Res. 48, 63-68. doi: 10.1269/jrr.06032

Hosseinimehr, S. J., Azadbakht, M., and Abadi, A. J. (2008). Protective effect of hawthorn extract against genotoxicity induced by cyclophosphamide in mouse bone marrow cells. Environ. Toxicol. Pharmacol. 25, 51-56. doi: 10.1016/ j.etap.2007.08.006

Hosseinimehr, S. J., Mahmoudzadeh, A., Azadbakht, M., and Akhlaghpoor, S. (2009). Radioprotective effects of Hawthorn against genotoxicity induced by gamma irradiation in human blood lymphocytes. Radiat. Environ. Biophys. 48, 95-98. doi: 10.1007/s00411-008-0190-z

Hosseinimehr, S. J., Azadbakht, M., Tanha, M., Mahmodzadeh, A., and Mohammadifar, S. (2011). Protective effect of hawthorn extract against genotoxicity induced by methyl methanesulfonate in human lymphocytes. Toxicol. Ind. Health 27, 363-369. doi: 10.1177/0748233710387010

Idris-Khodja, N., Auger, C., Koch, E., and Schini-Kerth, V. (2012). Crataegus special extract $\mathrm{WS}^{\circledR} 1442$ prevents aging-related endothelial dysfunction. Phytomedicine 19, 699-706. doi: 10.1016/j.phymed.2012.04.005

Jamwal, S., and Sharma, S. (2018). Vascular endothelium dysfunction: a conservative target in metabolic disorders. Inflamm. Res. 67, 391-405. doi: 10.1007/s00011-018-1129-8

Jayachandran, K. S., Khan, M., Selvendiran, K., Devaraj, S. N., and Kuppusamy, P. (2010). Crataegus oxycantha extract attenuates apoptotic incidence in myocardial ischemia-reperfusion injury by regulating Akt and HIF-1 signaling pathways. J. Cardiovasc. Pharmacol. 56, 526-531. doi: 10.1097/FJC.0b013e3181f64c51

Kadas, Z., Evrendilek, G. A., and Heper, G. (2014). The metabolic effects of hawthorn vinegar in patients with high cardiovascular risk group. J. Food Nutr. Res. 2, 539-545. doi: 10.12691/jfnr-2-9-2

Kao, E. S., Wang, C. J., Lin, W. L., Yin, Y. F., Wang, C. P., Tseng, T. H., et al. (2005). Anti-inflammatory potential of flavonoid contents from dried fruit of Crataegus pinnatifida in vitro and in vivo. J. Agric. Food. Chem. 53, 430-436. doi: $10.1021 / \mathrm{jf} 040231 \mathrm{f}$

Kim, S. J., Um, J. Y., Hong, S. H., and Lee, J. Y. (2011). Anti-inflammatory activity of hyperoside through the suppression of nuclear factor- $\mathrm{\kappa B}$ activation in mouse peritoneal macrophages. Am. J. Chin. Med. 39, 171-181. doi: 10.1142/S0192415X11008737

Kwok, C. Y., Li, C., Cheng, H. L., Ng, Y. F., Chan, T. Y., Kwan, Y. W., et al. (2013). Cholesterol lowering and vascular protective effects of ethanolic extract of dried fruit of Crataegus pinnatifida, hawthorn (Shan Zha), in diet-induced hypercholesterolaemic rat model. J. Funct. Foods. 5, 1326-1335. doi: 10.1016/ j.jff. 2013.04 .020

Li, C., and Wang, M. H. (2011). Anti-inflammatory effect of the water fraction from hawthorn fruit on LPS-stimulated RAW 264.7 cells. Nutr. Res. Pract. 5, 101-106. doi: 10.4162/nrp.2011.5.2.101

Li, T., Li, S., Du, L., Wang, N., Guo, M., Zhang, H., et al. (2010). Effects of haw pectic oligosaccharide on lipid metabolism and oxidative stress in experimental hyperlipidemia mice induced by high-fat diet. Food Chem. 121, 1010-1013. doi: 10.1016/j.foodchem.2010.01.039

Li, S., Li, T., Zhu, R., Wang, N., Song, Y., Wang, S., et al. (2013a). Antibacterial action of haw pectic oligosaccharides. Int. J. Food Prop. 16, 706-712. doi: 10.1080/10942912.2011.565904

Li, T. P., Zhu, R. G., Dong, Y. P., Liu, Y. H., Li, S. H., and Chen, G. J. (2013b). Effects of pectin pentaoligosaccharide from Hawthorn (Crataegus pinnatifida Bunge. var. major) on the activity and mRNA levels of enzymes involved in fatty acid oxidation in the liver of mice fed a high-fat diet. J. Agric. Food. Chem. 61, 7599-7605. doi: 10.1021/jf400283w

Li, T., Li, S., Dong, Y., Zhu, R., and Liu, Y. (2014). Antioxidant activity of pentaoligogalacturonide, isolated from haw pectin, suppresses triglyceride synthesis in mice fed with a high-fat diet. Food Chem. 145, 335-341. doi: 10.1016/ j.foodchem.2013.08.036

Li, S., Huang, Z., Dong, Y., Zhu, R., and Li, T. (2017). Haw pectin pentaglaracturonide inhibits fatty acid synthesis and improves insulin sensitivity in high-fat-fed mice. J. Funct. Foods. 34, 440-446. doi: 10.1016/ j.jff.2017.04.030

Libby, P., Ridker, P. M., and Maseri, A. (2002). Inflammation and atherosclerosis. Circulation 105, 1135-1143. doi: 10.1161/hc0902.104353

Little, P. J., Ballinger, M. L., and Osman, N. (2007). Vascular wall proteoglycan synthesis and structure as a target for the prevention of atherosclerosis. Vasc. Health Risk. Manage. 3, 117-124.

Liu, M., Zhang, W., and Liu, L. (2009a). Effect on PPAR $\gamma$, ABCA1 and CD36 mRNA in macrophage of apoprotein e knock out mice with extractive of giant knotweed rhizome and hawthorn [J]. Chin. J. Arterioscler. 17, 902-906.

Liu, P., Kallio, H., Lu, D., Zhou, C., Ou, S., Yang, B., et al. (2009b). Acids, sugars, and sugar alcohols in Chinese hawthorn (Crataegus spp.) fruits. J. Agric. Food. Chem. 58, 1012-1019. doi: 10.1021/jf902773v

Liu, X., Zhou, L., Liang, R., and Wang, P. (2009c). Study on lipid regulation mechanism of total flavonoids from Folium crataegi by 3T3-L1 cells. Chin. Arch. Tradit. Chin. Med. 27, 1066-1068.

Liu, P., Kallio, H., Lü, D., Zhou, C., and Yang, B. (2011). Quantitative analysis of phenolic compounds in Chinese hawthorn (Crataegus spp.) fruits by high performance liquid chromatography-electrospray ionisation mass spectrometry. Food Chem. 127, 1370-1377. doi: 10.1016/j.foodchem.2011.01.103

Liu, L., Zheng, G., Zhang, W., Guo, G., and Wu, M. (2014). Clinical study on treatment of carotid atherosclerosis with extraction of Polygoni Cuspidati Rhizoma et Radix and Crataegi Fructus: a randomized controlled trial. China J. Chin. Mater. Med. 39, 1115-1119.

Liu, S., Chang, X., Liu, X., and Shen, Z. (2016). Effects of pretreatments on anthocyanin composition, phenolics contents and antioxidant capacities during fermentation of hawthorn (Crataegus pinnatifida) drink. Food Chem. 212, 87-95. doi: 10.1016/j.foodchem.2016.05.146

Luo, Y., Chen, G., Li, B., Ji, B., Xiao, Z., Yi, G., et al. (2009). Dietary intervention with AHP, a functional formula diet, improves both serum and hepatic lipids profile in dyslipidemia mice. J. Food Sci. 74, H189-H195. doi: 10.1111/j.17503841.2009.01241.x

Mannarino, E., and Pirro, M. (2008). Endothelial injury and repair: a novel theory for atherosclerosis. Angiology 59 (2_suppl), 69S-72S. doi: 10.1177/ 0003319708320761

Moriya, J. (2019). Critical roles of inflammation in atherosclerosis. J. Cardiol. 73, 22-27. doi: 10.1016/j.jjcc.2018.05.010

Mraihi, F., Hidalgo, M., de Pascual-Teresa, S., Trabelsi-Ayadi, M., and Cherif, J.-K. (2015). Wild grown red and yellow hawthorn fruits from tunisia as source of antioxidants. Arab. J. Chem. 8, 570-578. doi: 10.1016/j.arabjc.2014.11.045

Myung, S. K., Ju, W., Cho, B., Oh, S. W., Park, S. M., Koo, B. K., et al. (2013). Efficacy of vitamin and antioxidant supplements in prevention of cardiovascular disease: systematic review and meta-analysis of randomised controlled trials. Br. Med. J. 346, f10. doi: 10.1136/bmj.f10

Olofsson, S. O., and Boren, J. (2005). Apolipoprotein B: a clinically important apolipoprotein which assembles atherogenic lipoproteins and promotes the development of atherosclerosis. J. Intern. Med. 258, 395-410. doi: 10.1111/ j.1365-2796.2005.01556.x

Pascual-Teresa, D., Moreno, D. A., and García-Viguera, C. (2010). Flavanols and anthocyanins in cardiovascular health: a review of current evidence. Int. J. Mol. 11, 1679-1703. doi: 10.3390/ijms11041679

Peng, Y., Lou, L. L., Liu, S. F., Zhou, L., Huang, X. X., Song, S. J., et al. (2016). Antioxidant and anti-inflammatory neolignans from the seeds of hawthorn. Bioorg. Med. Chem. 26, 5501-5506. doi: 10.1016/j.bmcl.2016.10.012

Perricone, A. J., and Vander Heide, R. S. (2014). Novel therapeutic strategies for ischemic heart disease. Pharmacol. Res. 89, 36-45. doi: 10.1016/j.phrs. 2014.08.004

Peters, W., Drueppel, V., Kusche-Vihrog, K., Schubert, C., and Oberleithner, H. (2012). Nanomechanics and sodium permeability of endothelial surface layer modulated by hawthorn extract WS 1442. PloS One 7, e29972. doi: 10.1371/ journal.pone.0029972

Petrovska, B. B. (2012). Historical review of medicinal plants' usage. Pharmacogn. Rev. 6, 1-5. doi: 10.4103/0973-7847.95849

Pittler, M. H., Schmidt, K., and Ernst, E. (2003). Hawthorn extract for treating chronic heart failure: meta-analysis of randomized trials. Am. J. Med. 114, 665674. doi: 10.1016/S0002-9343(03)00131-1

Rababa'h, A. M., Altarabsheh, S. E., Haddad, O., Deo, S. V., Obeidat, Y., and AlAzzam, S. (2016). Hawthorn herb increases the risk of bleeding after cardiac 
surgery: an evidence-based approach. Heart Surg. Forum. 19, E175-E179. doi: 10.1532/hsf. 1570

Ranjbar, K., Zarrinkalam, E., Salehi, I., Komaki, A., and Fayazi, B. (2018). Cardioprotective effect of resistance training and Crataegus oxyacantha extract on ischemia reperfusion-induced oxidative stress in diabetic rats. BioMed. Pharmacother. 100, 455-460. doi: 10.1016/j.biopha.2018.02.021

Reiner, Ž., Catapano, A. L., De Backer, G., Graham, I., Taskinen, M. R., Wiklund, O., et al. (2011). ESC/EAS guidelines for the management of dyslipidaemias: the task force for the management of dyslipidaemias of the European Society of Cardiology (ESC) and the European Atherosclerosis Society (EAS). Eur. Heart J. 32, 1769-1818. doi: 10.1093/eurheartj/ehr158

Ridker, P. M. (2019). Anticytokine agents: targeting interleukin signaling pathways for the treatment of atherothrombosis. Circ. Res. 124, 437-450. doi: 10.1161/CIRCRESAHA.118.313129

Roffi, M., Patrono, C., Collet, J. P., Mueller, C., Valgimigli, M., Andreotti, F., et al. (2016). 2015 ESC guidelines for the management of acute coronary syndromes in patients presenting without persistent st-segment elevation: task force for the management of acute coronary syndromes in patients presenting without persistent st-segment elevation of the European Society of Cardiology (ESC). Eur. Heart J. 37, 267-315. doi: 10.1093/eurheartj/ehv320

Shatoor, A. S., and Al Humayed, S. (2019). The protective effect of crataegus aronia against high-fat diet-induced vascular inflammation in rats entails inhibition of the nlrp-3 inflammasome pathway. Cardiovasc. Toxicol. 20, 82-99. doi: 10.1007/s12012-019-09534-9

Skålén, K., Gustafsson, M., Rydberg, E. K., Hultén, L. M., Wiklund, O., Innerarity, T. L., et al. (2002). Subendothelial retention of atherogenic lipoproteins in early atherosclerosis. Nature 417, 750-754. doi: 10.1038/nature00804

Stewart, J., Manmathan, G., and Wilkinson, P. (2017). Primary prevention of cardiovascular disease: a review of contemporary guidance and literature. JRSM Cardiovasc. Dis. 6, 2048004016687211. doi: 10.1177/2048004016687211

Stocker, R., and Keaney, J. F. Jr. (2004). Role of oxidative modifications in atherosclerosis. Physiol. Rev. 84, 1381-1478. doi: 10.1152/physrev.00047.2003

Sun, Z., Yan, B., Yu, W., Yao, X., Ma, X., Sheng, G., et al. (2016). Vitexin attenuates acute doxorubicin cardiotoxicity in rats via the suppression of oxidative stress, inflammation and apoptosis and the activation of FOXO3a. Exp. Ther. Med. 12, 1879-1884. doi: $10.3892 /$ etm. 2016.3518

Tauchert, M. (2002). Efficacy and safety of crataegus extract WS 1442 in comparison with placebo in patients with chronic stable New York heart association class-III heart failure. Am. Heart J. 143, 910-915. doi: 10.1067/mhj.2002.121463

Topal, G., Koç, E., Karaca, Ç., Altuğ, T., Ergin, B., Demirci, C., et al. (2013). Effects of crataegus microphylla on vascular dysfunction in streptozotocin-induced diabetic rats. Phytother. Res. 27, 330-337. doi: 10.1002/ptr.4726

Vandvik, P. O., Lincoff, A. M., Gore, J. M., Gutterman, D. D., Sonnenberg, F. A., Alonso-Coello, P., et al. (2012). Primary and secondary prevention of cardiovascular disease: antithrombotic therapy and prevention of thrombosis: american college of chest physicians evidence-based clinical practice guidelines. Chest 141, e637S-e668S. doi: 10.1378/chest.11-2306

Wang, N., Zhang, C., Qi, Y., and Li, T. (2007). Extraction and food chemical characterizations of haw pectins. Sci. Technol. Food Ind. 11, 87-92.

Wang, H., Zhang, Z., Guo, Y., Sun, P., Lv, X., and Zuo, Y. (2011). Hawthorn fruit increases the antioxidant capacity and reduces lipid peroxidation in senescence-accelerated mice. Eur. Food Res. Technol. 232, 743-751. doi: 10.1007/s00217-011-1435-7

Wang, T., Zhang, P., Zhao, C., Zhang, Y., Liu, H., Hu, L., et al. (2011). Prevention effect in selenite-induced cataract in vivo and antioxidative effects in vitro of Crataegus pinnatifida leaves. Biol. Trace Elem. Res. 142, 106-116. doi: 10.1007/ s12011-010-8752-8

Wang, W., Yang, B., Wang, L., Liang, R., Chen, C., Hu, N., et al. (2011). Antiatherogenic effect of Radix Salviae Miltiorrhizae and Fructus Crataegi on experimental atherosclerosis in rats. China J. Chin. Mater. Med. 36, 784-789.

Wang, J., Xiong, X., and Feng, B. (2013). Effect of crataegus usage in cardiovascular disease prevention: an evidence-based approach. Evid. -Based Complementary Altern. Med. 2013, 149363. doi: 10.1155/2013/149363

Wang, S., Wu, M., Chen, K., Liu, Y., Sun, J., Sun, Z., et al. (2019). Hawthorn extract alleviates atherosclerosis through regulating inflammation and apoptosis related factors: an experimental study. Chin. J. Integr. Med. 25, 108-115. doi: 10.1007/s11655-018-3020-4

Weber, C., and Noels, H. (2011). Atherosclerosis: current pathogenesis and therapeutic options. Nat. Med. 17, 1410. doi: 10.1038/nm.2538

Willer, E. A., Malli, R., Bondarenko, A. I., Zahler, S., Vollmar, A. M., Graier, W. F., et al. (2012). The vascular barrier-protecting hawthorn extract WS ${ }^{\circledR}$ 1442 raises endothelial calcium levels by inhibition of SERCA and activation of the IP3 pathway. J. Mol. Cell Cardiol. 53, 567-577. doi: 10.1016/j.yjmcc.2012.07.002

Wu, J., Peng, W., Qin, R., and Zhou, H. (2014). Crataegus pinnatifida: chemical constituents, pharmacology, and potential applications. Molecules 19, 16851712. doi: $10.3390 /$ molecules 19021685

Xie, W., Sun, C., and Liu, S. (2009). Effect of hawthorn flavanone on blood-fat and expression of lipogenesis and lipolysis genes of hyperlipidemia model mouse. China J. Chin. Mater. Med. 34, 224-229.

Xiyun, Y., and Yaofa, W. (2002). Protective effects of hawthorn leaves flavonoids on oxidation induced damages of vascular endothelial cells in vitro. Chin. J. Mod. Appl. Pharm. 4, 265-268.

Yang, G., Wang, Y., Zeng, Y., Gao, G., Liang, X., Zhou, M., et al. (2013). Rapid health transition in China 1990-2010: findings from the global burden of disease study 2010. Lancet 381, 1987-2015. doi: 10.1016/S0140-6736(13) 61097-1

Yonekubo, B. T., Alves, H. M. C., de Souza Marques, E., Perazzo, F. F., Rosa, P. C. P., Gaivão, I. O. M., et al. (2018). The genotoxic effects of fruit extract of Crataegus oxyacantha (hawthorn) in mice. J. Toxicol. Environ. Health A. 81, 974-982. doi: $10.1080 / 15287394.2018 .1503982$

Yoo, J. H., Liu, Y., and Kim, H. S. (2016). Hawthorn fruit extract elevates expression of $\mathrm{Nrf} 2 / \mathrm{HO}-1$ and improves lipid profiles in ovariectomized rats. Nutrients 8, 283. doi: 10.3390/nu8050283

Zhang, Z., Chang, Q., Zhu, M., Huang, Y., Ho, W. K., and Chen, Z. Y. (2001). Characterization of antioxidants present in hawthorn fruits. J. Nutr. Biochem. 12, 144-152. doi: 10.1016/S0955-2863(00)00137-6

Zhang, Z., Ho, W. K., Huang, Y., and Chen, Z. Y. (2002a). Hypocholesterolemic activity of hawthorn fruit is mediated by regulation of cholesterol- $7 \alpha$ hydroxylase and acyl CoA: cholesterol acyltransferase. Food. Res. Int. 35, 885-891. doi: 10.1016/S0963-9969(02)00099-6

Zhang, Z., Ho, W. K., Huang, Y., James, A. E., Lam, L. W., and Chen, Z. Y. (2002b). Hawthorn fruit is hypolipidemic in rabbits fed a high cholesterol diet. J. Nutr. 132, 5-10. doi: 10.1093/jn/132.1.5

Zhang, J., Liang, R., Wang, L., Yan, R., Hou, R., Gao, S., et al. (2013). Effects of an aqueous extract of Crataegus pinnatifida Bge. var. major $\mathrm{NE} \mathrm{Br}$. fruit on experimental atherosclerosis in rats. J. Ethnopharmacol. 148, 563-569. doi: 10.1016/j.jep.2013.04.053

Zhang, Y., Zhang, L., Geng, Y., and Geng, Y. (2014). Hawthorn fruit attenuates atherosclerosis by improving the hypolipidemic and antioxidant activities in apolipoprotein e-deficient mice. J. Atheroscler. Thromb. 21, 119-128. doi: $10.5551 /$ jat. 19174

Zheng, G. j., ZHU, Y., and Wang, T. (2010). Effect of polygonum cuspidatum and hawthorn on anti-atherosclerosis unstable plaque. Chin. J. Pathophysio. 26, 635-639.

Zheng, X., Li, X., Chen, M., Yang, P., Zhao, X., Zeng, L., et al. (2019). The protective role of hawthorn fruit extract against high salt-induced hypertension in Dahl salt-sensitive rats: impact on oxidative stress and metabolic patterns. Food Funct. 10, 849-858. doi: 10.1039/C8FO01818A

Zhu, R., Li, T., Dong, Y., Liu, Y., Li, S., Chen, G., et al. (2013). Pectin pentasaccharide from hawthorn (Crataegus pinnatifida Bunge. var. major) ameliorates disorders of cholesterol metabolism in high-fat diet fed mice. Food Res. Int. 54, 262-268. doi: 10.1016/j.foodres.2013.07.010

Zhu, R. G., Sun, Y. D., Li, T. P., Chen, G., Peng, X., Duan, W. B., et al. (2015). Comparative effects of hawthorn (Crataegus pinnatifida Bunge) pectin and pectin hydrolyzates on the cholesterol homeostasis of hamsters fed highcholesterol diets. Chem.-Biol. Interact. 238, 42-47. doi: 10.1016/ j.cbi.2015.06.006

Zhu, R. G., Sun, Y. D., Hou, Y. T., Fan, J. G., Chen, G., and Li, T. P. (2017). Pectin penta-oligogalacturonide reduces cholesterol accumulation by promoting bile 
acid biosynthesis and excretion in high-cholesterol-fed mice. Chem.-Biol. Interact. 272, 153-159. doi: 10.1016/j.cbi.2017.05.018

Zhu, Y., Feng, B., He, S., Su, Z., and Zheng, G. (2018). Resveratrol combined with total flavones of hawthorn alleviate the endothelial cells injury after coronary bypass graft surgery. Phytomedicine 40, 20-26. doi: 10.1016/j.phymed. 2017.12.037

Zhu, R., Zhang, X., Wang, Y., Zhang, L., Wang, C., Hu, F., et al. (2019). Pectin oligosaccharides from hawthorn (Crataegus pinnatifida Bunge. var. major): molecular characterization and potential antiglycation activities. Food Chem. 286, 129-135. doi: 10.1016/j.foodchem.2019.01.215
Conflict of Interest: The authors declare that the research was conducted in the absence of any commercial or financial relationships that could be construed as a potential conflict of interest.

Copyright $\odot 2020 \mathrm{Wu}$, Liu, Xing, Yang, Li and Cao. This is an open-access article distributed under the terms of the Creative Commons Attribution License (CC BY). The use, distribution or reproduction in other forums is permitted, provided the original author(s) and the copyright owner(s) are credited and that the original publication in this journal is cited, in accordance with accepted academic practice. No use, distribution or reproduction is permitted which does not comply with these terms. 